\title{
Ube2s regulates Sox2 stability and mouse ES cell maintenance
}

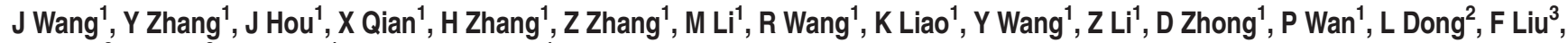 \\ $X$ Wang $^{2}, Y$ Wan $^{3}$, W Xiao, and WW Zhang ${ }^{*, 1}$
}

Sox2 has a critical role in embryonic stem (ES) cell maintenance and differentiation. Interestingly, its activity is highly dosagedependent. Although transcriptional regulation of Sox2 has been extensively studied, the mechanisms orchestrating its degradation remain unclear. In this study, we identified ubiquitin-conjugating enzyme E2S (Ube2s) as a novel effector for Sox2 protein degradation. Ube2s mediates K11-linked polyubiquitin chain formation at the Sox2-K123 residue, thus marking it for proteasome-mediated degradation. Besides its role in fine-tuning the precise level of Sox2, Ube2s reinforces the self-renewing and pluripotent state of ES cells. Importantly, it also represses Sox2-mediated ES cell differentiation toward the neural ectodermal lineage.

Cell Death and Differentiation (2016) 23, 393-404; doi:10.1038/cdd.2015.106; published online 21 August 2015

Mouse embryonic stem (mES) cells display a unique selfrenewing and pluripotent state. ${ }^{1}$ Transcription factor Sox 2 is one of the core regulators indispensable for ES cell maintenance. $^{2}$ Interestingly, the role of Sox2 is highly dosage-dependent. Both its elevation and depletion can trigger ES cell differentiation. ${ }^{3-5}$ It is of great interest to dissect the mechanisms controlling the precise level of Sox2 in ES cells. Although extensive studies have uncovered how Sox2 is transcriptionally activated or repressed, ${ }^{2,6}$ posttranslational regulation of Sox2, in general, and its degradation, in particular, remains to be elucidated. A recent study ${ }^{7}$ shows that the HECT domain-containing E3 Wwp2 promotes Sox2 degradation through ubiquitination; however, this regulation appears to be largely restricted to methylated Sox2.

In eukaryotic cells, ubiquitin (Ub) can form a polymer chain at any of its seven lysine $(\mathrm{K})$ residues, namely $\mathrm{K} 6, \mathrm{~K} 11, \mathrm{~K} 27, \mathrm{~K} 29$, $\mathrm{K} 33, \mathrm{~K} 48$ and $\mathrm{K} 63$, to covalently modify target proteins and thus regulate their activity in various biological processes. ${ }^{8,9}$ Among them, K48-linked polyubiquitin chain is thought to be a principal signal destining proteins for $26 \mathrm{~S}$ proteasomemediated proteolysis. ${ }^{10-12}$ Compared with K48- and K63-linked polyubiquitination whose biological significance has been extensively studied, the cellular function of K11-linked polyubiquitination is not well understood. Recently, several studies profiled the polyubiquitin signals in neurodegenerative diseases, such as Alzheimer's disease, and found that although the K11 linkage only accounts for a very small percentage of the total ubiquitination content in normal mammalian cells, its accumulation is markedly increased in the neurodegenerative disorder samples. ${ }^{13-15}$ This correlation highlights a putative role of key enzymatic machineries responsible for $\mathrm{K} 11$ polyubiquitin assembly in the process of neurogenesis, which is further supported by the observation that anaphase-promoting complex (APC), an E3 complex governing K11 polyubiquitination, regulates neuronal morphogenesis and differentiation. ${ }^{16}$ Of note, Sox2 is highly expressed in the neurogenetic tissues, such as the hippocampus and central canal, and has a critical role in unperturbed neurogenesis. ${ }^{17-19}$ These insights corroborate our interest in exploring the role of $\mathrm{K} 11$-linked polyubiquitin chain assembly machineries in fine-tuning the precise level of Sox2 in mES cells.

At the molecular level, Ub-conjugating enzyme E2S (Ube2s) acts together with E1, a priming E2 (Ube2c/d) and the E3 complex APC to elongate K11-linked polyubiquitin chain on substrates. $^{20,21}$ A recent study further clarifies that Ube2s governs the efficiency of substrate degradation through the formation of branched K11-linked polyubiquitin chains. ${ }^{22}$ In this study, we identified Ube2s as a novel critical regulator of mES cells. It ubiquitinates Sox 2 through a direct protein-protein interaction at its $\mathrm{K} 123$ residue, thus marking Sox2 for proteasomal degradation. This regulatory activity of Ube2s contributes to mES cell maintenance and Sox2-controlled differentiation toward neuroectoderm. The findings in this study provide new insights into ES cell regulation and fate specification.

\section{Results}

Ube2s and Apc10 interact with Sox2 in mouse ES cells. Multiple factors are involved in the process of $\mathrm{K} 11$ linked polyubiquitin chain formation, including Ube2c, Ube2s,

\footnotetext{
${ }^{1}$ College of Life Sciences, Capital Normal University, Beijing, China; ${ }^{2}$ Department of Neurobiology, Capital Medical University, Beijing, China and ${ }^{3}$ Neuroscience Research Institute, Peking University, Beijing, China

*Corresponding author: WW Zhang or W Xiao, College of Life Sciences, The Capital Normal University, No. 732, Lab Building, 105 Xi San Huan Bei Road, Hai Dian District, Beijing 100048, China. Tel: +86 1068909575605 or +86 10 68903412; Fax: +86 10 68909617; E-mail: zhangww@cnu.edu.cn or weixiao@cnu.edu.cn

Abbreviations: AP, alkaline phosphatase; APC, anaphase-promoting complex; Cdc20, cell division cycle protein 20; Cdc27, cell division cycle protein 27; Cdh1, Cdc20homolog 1; CK, vector transfection control; DES, diethylstilbestrol; IP, immunoprecipitation; K, lysine; mES cells, mouse embryonic stem cells; mSox2, Sox2 mutant in which a $\mathrm{K}$ residue is substituted with $\mathrm{R}$; mUbe2s, full-length Ube2s with C95S mutation; OE, overexpression; qRT-PCR, quantitative real-time RT-PCR; R, arginine; RA, retinoic acid; Ub, ubiquitin; Ube2s, ubiquitin-conjugating enzyme E2S

Received 13.2.2015; revised 21.6.2015; accepted 01.7.2015; Edited by JA Cidlowski; published online 21.8.15
} 
Cdc20-homolog 1 (Cdh1), cell division cycle protein 20 (Cdc20), cell division cycle protein 27 (Cdc27) and APCs (reviewed in Peters ${ }^{23}$ ). We inferred that if $\mathrm{K} 11$ linkage regulates Sox 2 degradation, these factors may be closely correlated with $\mathrm{mES}$ cell differentiation. Therefore, we treated mES cells with retinoic acid (RA) to induce cell differentiation. Total RNAs were extracted for quantitative real-time RT-PCR analysis to monitor expression changes in these factors, which shows that Ube2s and Apc10 expressions were most sensitive to mES cell differentiation and exhibited the most striking downregulation (Supplementary Figure S1). This observation suggests that Ube2s and Apc10 serve as key ubiquitination regulators of Sox 2 in the process of $\mathrm{mES}$ cell maintenance and differentiation.

We reasoned that if Ube2s and Apc10 are involved in ubiquitinating Sox2 in mES cells, they may physically interact with Sox2. Immunocytochemistry staining analysis shows that both Ube2s and Sox2 are ubiquitiously distributed in the cytoplasm and nucleus of mES cells (Figure 1a). However, after pre-extracting soluble fractions from mES cells, we did not observe Ube2s foci formed on chromatin, suggesting that the association of Ube2s with Sox2 is likely to be in the chromatin-free fraction (Figure 1b). Nevertheless, the interaction between endogenous Ube2s and Sox2 can be detected by a co-immunoprecipitation (IP) assay in mES cells (Figure 1c). Furthermore, a pull-down assay using purified recombinant Ube2s and Sox2 proteins confirms their direct physical association in vitro (Figures 1d and e). Ube2s contains well-characterized domains including an $\mathrm{N}$ terminus (1-13 aa), a Ubc domain and a C-terminal extension. ${ }^{24}$ To identify the specific region in Ube2s critical for its association with Sox2, we constructed a series of Ube2s truncations (Figure 1f, left panel). Our results show that the Ubc domain is essential and sufficient for mediating the association between Ube2s and Sox2 (Figure 1f, right panel). Interestingly, the enzymatically inactive C95S mutation ${ }^{21}$ within the Ubc domain abrogates the interaction of Ube2s with Sox2 (Figure 1f). Consistently, full-length Ube2s with C95S mutation also fails to bind Sox2, thus confirming the critical role of C95 in this interaction (Figures $1 \mathrm{~g}$ and $\mathrm{h}$ ).

We also detected a physical interaction between Apc10 and Sox 2 in mES cells (Supplementary Figures S2a and b), which is in agreement with the previous notion that Apc10 is responsible for substrate recognition. ${ }^{23}$

Ube2s ubiquitinates Sox2 and destines it for proteasomal degradation. Next, we sought to determine whether Ube2s and Apc10 regulate Sox2 degradation. Although Apc10 interference fails to enhance the stability of Sox2 (Supplementary Figure S2c), Ube2s depletion markedly delays Sox2 degradation (Figure $2 \mathrm{a}$ and Supplementary Figure S3a). Consistently, Ube2s overexpression accelerates Sox2 degradation (Figure $2 \mathrm{~b}$ and Supplementary Figure S3b). To determine whether Sox2 stability is regulated by proteasome-mediated protein degradation, we treated mES cells with the proteasome inhibitor MG132 in the presence of $\mathrm{CHX}$ to prevent de novo protein synthesis. MG132 treatment indeed stalls Sox2 degradation (Supplementary Figure S3c). Furthermore, Ube2s overexpression-enhanced Sox2 degradation is completely blocked by MG132 (Figure 2c and Supplementary Figure S3d), showing that Ube2s-promoted Sox2 degradation is dependent on the $26 \mathrm{~S}$ proteasome. The vector-transfected cells exhibit results similar to those of wildtype ES cells (Supplementary Figure S3e). Based on the above observations, we conclude that Ube2s has a critical role in regulating Sox2 stability.

To ask whether Ube2s mediates Sox2 polyubiquitination, we first examined the association of Sox2 with other known Ube2s partners, such as Cdh1 and Cdc20, which function as key activators required by Ube2s-mediated polyubiquitination. ${ }^{24}$ It was found that Cdh1, but not Cdc20, can be co-immunoprecipitated with Sox2 and Ube2s in mES cells (Supplementary Figures S4a and b). Failure in detecting the interaction between Cdc20 and Ube2s/Sox2 could be because of the extremely low level of Cdc20 in mES cells (Supplementary Figure S4c). The clear bands of Cdc20 shown in the mES cell extract input in Supplementary Figures S4a and $b$ were because of fourfold overloading compared with Cdh1. An in vitro ubiquitination assay reveals that Ube2s significantly increases the density of the polyubiquitin chains on Sox2, although it does not appear to alter average chain length (Figure $2 \mathrm{~d}$ ). This could be because of endogenous Ube2s proteins copurified with its E3 APC ${ }^{\text {Cdc27 }}$ complex. $^{21}$ A previous study showed that Ube2s mediates K11-linked polyubiquitin chain assembly on substrates. ${ }^{21}$ To verify this, we used a Ub-K11R mutant to perform the in vitro ubiquitination assay and found that this mutation significantly reduces the assembly of polyubiquitin chain on Sox2 (Figure 2d), suggesting that Ube2s modifies Sox2 through the formation of K11-linked polyubiquitin chains. Furthermore, Ube2s-overexpressed mES cells exhibit a robust elevation of polyubiquitinated Sox2 signal, confirming the capability of Ube2s in ubiquitinating Sox2 in vivo (Figure 2e). Taken together, we conclude that Ube2s ubiquitinates Sox2 via a direct

\footnotetext{
Figure 1 Ube2s is a novel interaction partner of Sox2. (a) Immunocytochemistry to analyze cellular localization of endogenous Ube2s (green) and Sox2 (red) in mES cells. Cell nuclei were stained with DAPI (4',6-diamidino-2-phenylindole) (blue). The photographs were taken with x400 magnification. (b) Immunocytochemistry following pre-extraction to remove soluble fractions. The photographs were taken with $\times 400$ magnification. Scale bars in (a and $\mathbf{b}$ ) represent $25 \mu \mathrm{m}$. (c) Co-IP to detect the association of Ube2s with Sox2. $\mathrm{mES}$ cell extracts were subjected to co-IP with the antibody against Sox2 (upper panel) or Ube2s (lower panel), followed by western blotting with antibodies against Ube2s and Sox2, respectively. (d) A pull-down assay to analyze the direct association of Ube2s with Sox2. Purified glutathione S-transferase (GST)-tagged Ube2s was conjugated to glutathione-sepharose beads, and subsequently incubated with purified His-tagged Sox2. The elution was analyzed by western blot using the anti-Sox2 antibody. GST alone was used as a control. (e) Glutathione-sepharose beads were used to bind GST-tagged Sox2 so as to capture His-tagged Ube2s. (f) GST-tagged and -truncated Ube2s were conjugated to glutathione-sepharose beads to capture His-tagged Sox2. (Left panel) Schematic diagram of the wild-type and truncated forms of Ube2s. Red asterisk in the left panel: C95S mutation; red asterisks in the right panel: the target Ube2s fragments. (g) Purified GST-tagged mUbe2s was conjugated to glutathione-sepharose beads to capture His-tagged Sox2. (h) Co-IP to detect the interaction between Ube2s-C95S and Sox2. mES cells were transfected with the construct expressing Flag-tagged Ube2s-C95S. Forty-eight hours after transfection, cell extracts were immunoprecipitated with anti-Flag antibody, followed by western blotting with antibodies against Sox2 and Flag. Flag-tagged wild-type Ube2s served as a positive control. CK, vector transfection control. The data presented are based on three independent repeats
} 
protein-protein association and thus destines it for $26 \mathrm{~S}$ proteasome-mediated degradation.

To determine the exact lysine residue(s) of Sox2 ubiquitinated by Ube2s, we first purified different domain truncations of Sox2 to identify domain(s) required for the Ube2s interaction, and found that both the HMG and TAD1 domains of Sox2 are capable of directly interacting with Ube2s (Figure 2f). As ubiquitination is restricted to the $\mathrm{K}$ residues of substrates, we then purified a series of Sox2 mutants in which every $K$ residue was substituted with an arginine $(R)$. An in vitro ubiquitination assay reveals that a Sox2-K123R mutation on its TAD1 domain abolishes Ube2s-mediated ubiquitination of Sox2 (Figure $2 \mathrm{~g}$ ), whereas other mutations do not exhibit such an effect (Supplementary Figure S5). Taken together, we conclude that Ube2s facilitates Sox2 ubiquitination primarily at its $\mathrm{K} 123$ site. a

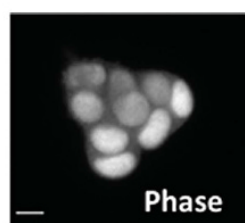

b

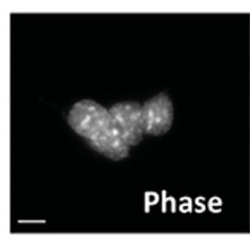

c

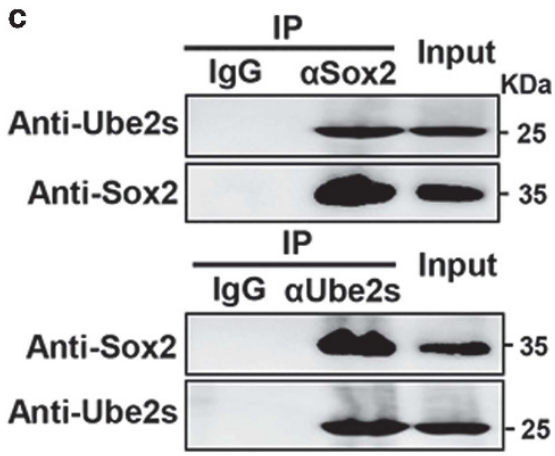

f
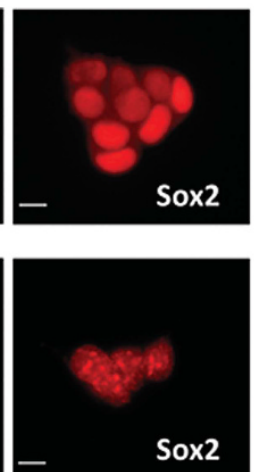
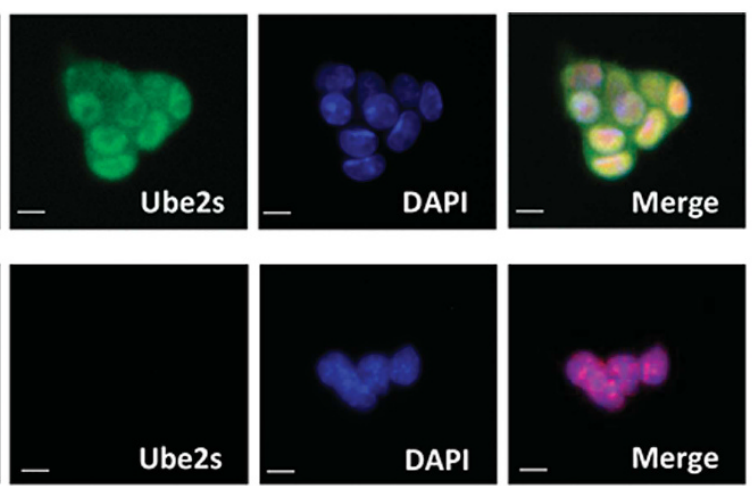

d

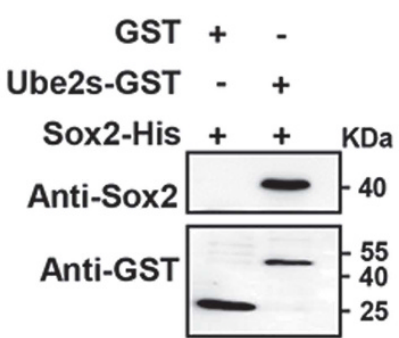

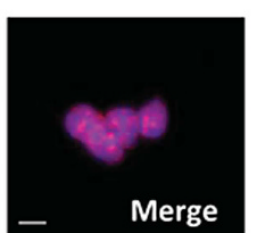

e

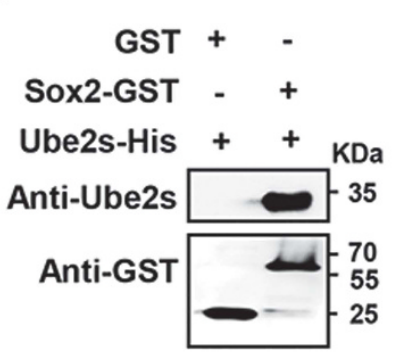

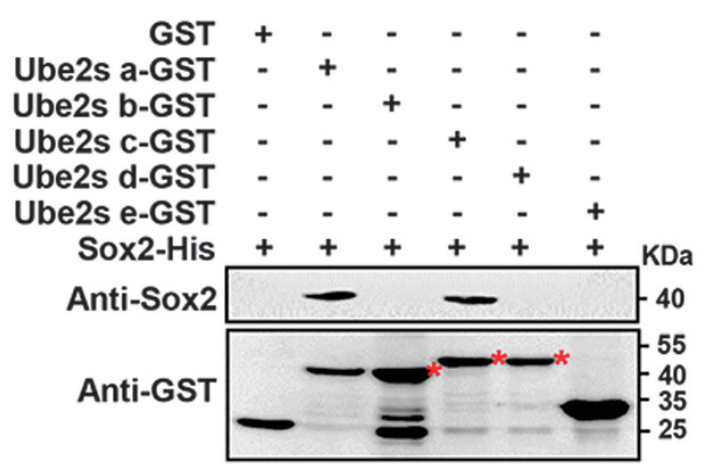

g

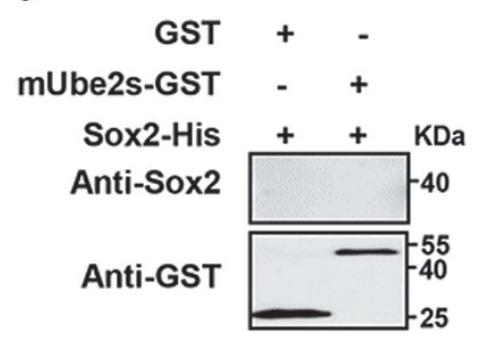

h

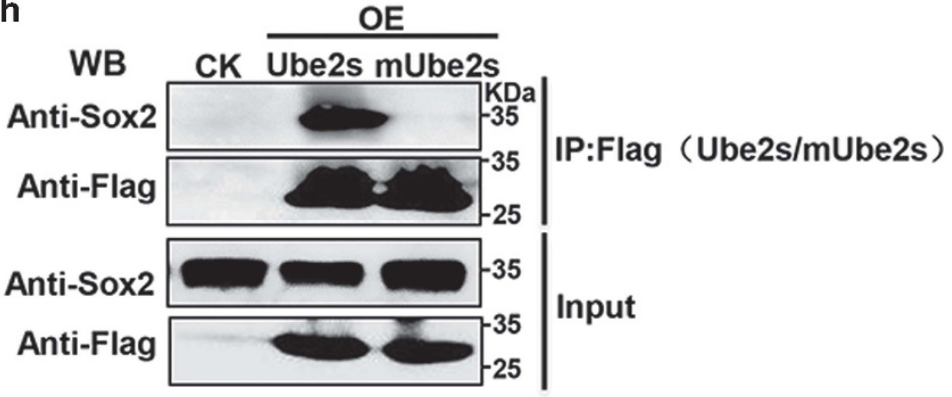


The functional relevance of Ube2s-promoted Sox2 degradation. As Sox2 maintains ES cells primarily through its activity as a transcription factor, ${ }^{2,6,25}$ we examined whether Ube2s suppresses Sox2-mediated transcriptional regulation. We used a luciferase assay with a reporter construct harboring a Sox2-targeted Nanog promoter. $^{2}$ This reporter was co-transfected with the construct overexpressing Ube2s and/or Sox2 into the embryonic kidney 293 cells. An enzymatically inactive Ube2s-C95S mutant (mUbe2s) was also included as a negative control. Western blot analysis shows successful overexpression of Ube2s/mUbe2s and Sox2 in the transfected cells (Figure 3a). We noticed that Ube2s overexpression alone exerts no effect on the reporter activity; however, it completely abolishes Sox2-induced promoter activation (Figure $3 a$ ). In contrast, mUbe2s overexpression fails to repress the Sox2 activity toward the Nanog promoter (Figure 3a). This result confirms an enzymedependent repressive role of Ube2s in Sox2-regulated transcription.

Thomson et al. ${ }^{26}$ reported that Sox2 elevation promotes ES cell differentiation into the neural ectoderm lineage. We asked whether Ube2s could inhibit Sox2-induced neuroectoderm differentiation from mES cells. To this end, we co-transfected Sox2- and Ube2s (or mUbe2s)-overexpressing constructs into mES cells, and subsequently drove them for a directed neuroectodermal differentiation. Vector transfection and single overexpression of Sox2, Ube2s or mUbe2s were used as controls. In line with the finding by Thomson et al., ${ }^{26}$ Sox2 overexpression successfully enhances the activation of neural ectoderm makers such as Sox1 and $\beta$ III-tubulin (Figures 3b and c). Strikingly, this induction is markedly abrogated by elevated Ube2s, whereas Ube2s-C95S overexpression does not show such an effect (Figures $3 b$ and c). Consistently, overexpression of Ube2s alone, but not $m U$ Ube2s, is capable of inhibiting neuroectodermal differentiation (Figures $3 b$ and $c$ ). As the Ube2s-mediated ubiquitin chain is specifically attached to the Sox2-K123 residue (Figure $2 \mathrm{~g}$ and Supplementary Figure S5), we asked whether the Sox2-K123R mutation could rescue Ube2s-inhibited neuroectodermal differentiation. To achieve this, we overexpressed both Ube2s and Sox2$K 123 R$ in ES cells for directed neuroectodermal differentiation. The Sox2-K119R mutation was used as a negative control. Results show that both Sox2-K119R and -K123R mutant similarly enhanced neuroectodermal differentiation of ES cells. However, when Sox $2-\mathrm{K} 123 \mathrm{R}$ is overexpressed with Ube2s, the expression of Sox1 or Blll-tubulin is no longer delayed, whereas the Sox2-K119R mutation remains under the control of Ube2s (Supplementary Figure S6). Therefore, we conclude that Ube2s is involved in regulating ES cell differentiation by ubiquitinating Sox 2 .

Ube2s has a critical role in maintaining the undifferentiated state of mES cells. To investigate the biological role of Ube2s in mES cells, we depleted Ube2s using shRNA and found that it markedly compromises the red staining signal for alkaline phosphatase (AP) (Figure 4a). Consistent with the observation in Figure 2, the protein level of Sox2 is increased (Figure 4a). Concomitantly, downregulation of self-renewal markers and upregulation of lineage-specific genes further confirms the differentiation of ES cells (Figure 4b). An additional Ube2s shRNA construct shows similar results (Supplementary Figure S7), ruling out the possibility of off-target effect. As expected, Apc10 depletion does not result in ES cell differentiation (Supplementary Figure S8). To further characterize the Ube2s-depleted ES cells, we performed a cell replating assay and found that these cells exhibit a markedly reduced capability in forming colonies, suggesting loss in self-renewal (Figure 4c). On the other hand, ES cells with ectopic Ube2s expression sustains a positive AP staining signal (Figure 4d), and these cells display capability in forming colonies similar to the control (Figure 4e).

Ube2s elevation reinforces the pluripotency of mES cells. Furthermore, we found that in the Ube2s-overexpressed ES cells, the mRNA levels of most self-renewal genes does not exhibit obvious changes (Figure 5a). Noteworthy, the expression of a key self-renewal marker Esrrb is markedly induced. Moreover, through titrating the amount of plasmids for transfection, it was found that increased Esrrb expression correlates strongly with the cellular Ube2s level (Figure 5a). Consistently, the protein level of Esrrb is also increased by Ube2s elevation (Figure 5b). As Ube2s does not bind to chromatin (Figure 1b), which excludes the possibility of direct transcriptional activation, we speculated that Ube2s is involved in

Figure 2 Ube2s ubquitinates Sox2 for proteasomal degradation. (a) Ube2s depletion delays Sox2 degradation. The construct expressing Ube2s shRNA was transfected into $\mathrm{mES}$ cells. After a 2-day antibiotic selection, the cells were treated with $12.5 \mu \mathrm{g} / \mathrm{ml} \mathrm{CHX}$ for the indicated hours. Relevant band intensities from western blot were measured by MultiGauge software (Fujifilm, Tokyo, Japan), and numbers represent Sox2/ $\beta$-tubulin ratios at different time points after CHX treatment (time 4 and $8 \mathrm{~h}$ ) normalized to the corresponding untreated controls (time 0). (b) Elevated Ube2s promotes Sox2 degradation. The construct overexpressing HA-tagged Ube2s was transfected into mES cells. Experimental design and procedures are as described in (a). OE: overexpression. (c) MG132 treatment abolishes Ube2s-promoted Sox2 degradation. mES cells were transfected with the construct overexpressing Ube2s. After a 2-day antibiotic selection, the cells were treated with $25 \mu \mathrm{M} \mathrm{MG132}$ and $12.5 \mu \mathrm{g} / \mathrm{ml} \mathrm{CHX}$ (dissolved in dimethyl sulfoxide (DMSO)) for the indicated hours. Equivalent amounts of DMSO serve as negative controls. (d) Ube2s-mediated Sox2 ubiquitination in vitro. The reaction components for in vitro ubiquitination assay include purified His ${ }_{6}$-tagged Ub, the E3 APC ${ }^{\text {Cdc27 }}$ complex co-immunoprecipitated by Cdc27 from mES cells ${ }^{21}$ and purified E1 (Uba1), glutathione $S$ transferase (GST)-tagged Ube2c, GST-tagged Ube2s and His $s_{6}$-tagged Sox2 proteins. The reaction solution was analyzed by western blot with an anti-Sox2 antibody. (e) Ube2s promotes Sox2 ubiquitination in vivo. mES cells were transfected with a construct expressing Ube2s. After $48 \mathrm{~h}, 3 \mu \mathrm{M}$ MG132 was added to treat cells for $15 \mathrm{~h}$. Whole-cell proteins were prepared for co-IP analysis with an anti-Sox2 antibody, followed by western blotting with an anti-Ub antibody. An anti- $\beta$-tubulin antibody was included as a loading control. (f) Purified GST-tagged Sox2 truncations were conjugated to glutathione-sepharose beads to capture His 6 -tagged Ube2s. GST was used as a negative control. Sox2: full-length Sox2; Sox2a: the N-terminal domain of Sox2 (aa 1-40); Sox2b: the HMG domain of Sox2 (aa 41-120); Sox2c: the TAD1 domain of Sox2 (aa 121-204); Sox2d: the serine-rich region of Sox2 (aa 205-263); Sox2e: the TAD2 domain of Sox2 (aa 264-319). Red asterisks: the target Sox2 fragments. (g) In vitro ubiquitination assay to identify Sox2-K123 as the ubiquitination site by Ube2s. GST-tagged Sox2 and Sox2-K123R were purified for the in vitro ubiquitination assay. The data presented are based on three independent repeats. KD, knockdown; CK, vector transfection control 
certain signaling pathways that regulate Esrrb expression. Previous studies indicate that the Gsk3- $\beta$-catenin-Tcf3 axis is a dominant pathway that suppresses Esrrb transcription, and the association of $\beta$-catenin with Tcf3 can convert the repressive role of Tcf3 in transcription. ${ }^{27-29}$ Interestingly, in breast cancer cells, Sox2 can directly interact with $\beta$-catenin, ${ }^{30}$ a phenomenon also observed in mES cells in this study (Figure $5 \mathrm{c}$ ), which points to a possibility that Ube2s overexpression-induced Sox2 degradation results in the release of $\beta$-catenin from the Sox2 complex, which subsequently binds Tcf3 to abolish its repression of Esrrb. To test this hypothesis, we obtained the nuclear extracts of the Ube2s-overexpressed ES cells. Western blotting analysis results showed that the protein level of Tcf3 does not exhibit any obvious change (Figure $5 \mathrm{~d}$ ). However, compared with the mock control, more $\beta$-catenin was precipitated in Ube2soverexpressed ES cells, and the interaction between $\beta$-catenin and Tcf3 is thus increased (Figure $5 \mathrm{~d}$ ), which could explain the enhanced transcription of Esrrb. Importantly, the increased $\beta$-catenin and Tcf3 association induced

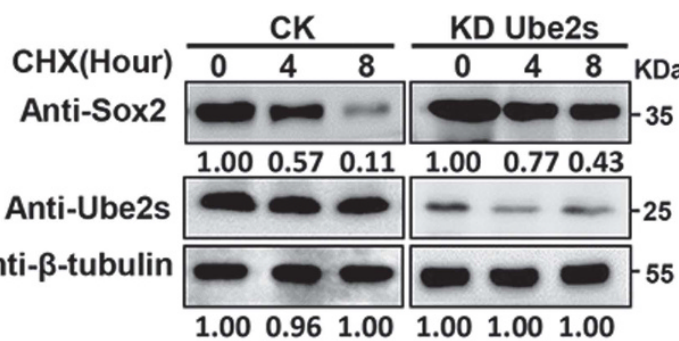

b

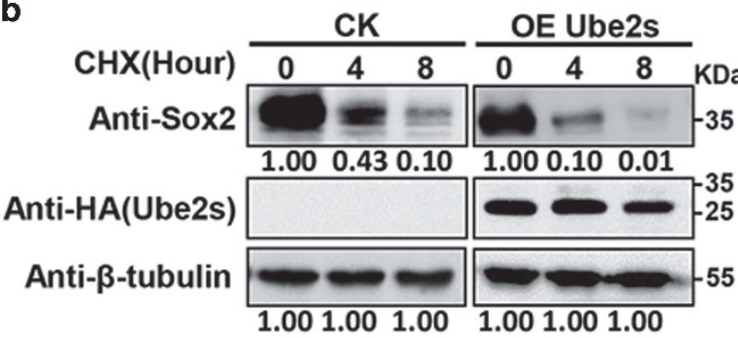

C

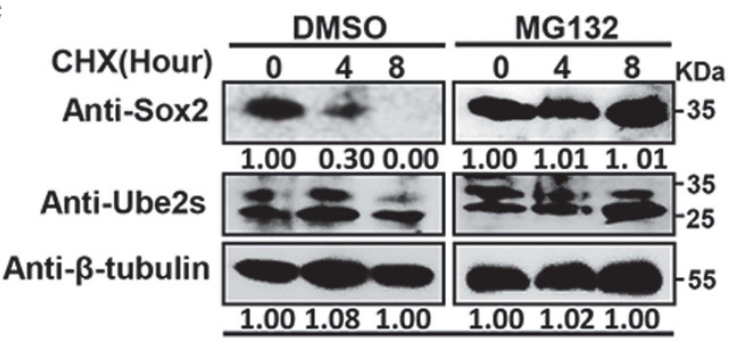

OE Ube2s

d

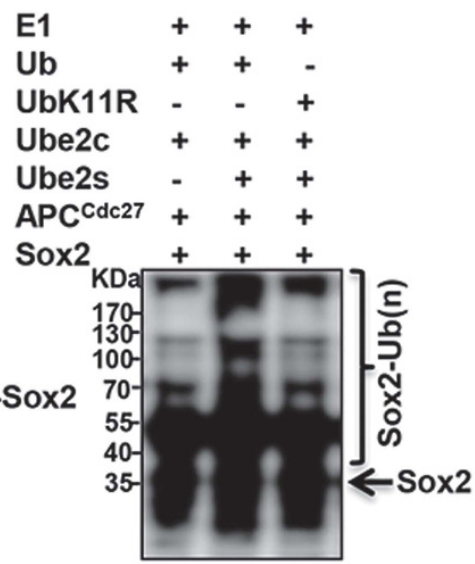

e



f

aa

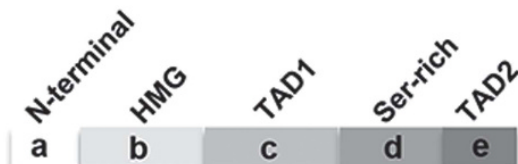

Sox2 GST

Sox2-GST

Sox2 c-GST

Sox2 d-GST - $\quad-\quad-\quad-\quad-\quad+$

Sox2 e-GST - $\quad-\quad-\quad-\quad-\quad-\quad+$

Ube2s-His $+++++++\mathrm{KDa}$

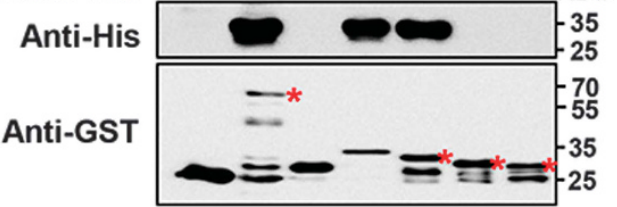

g

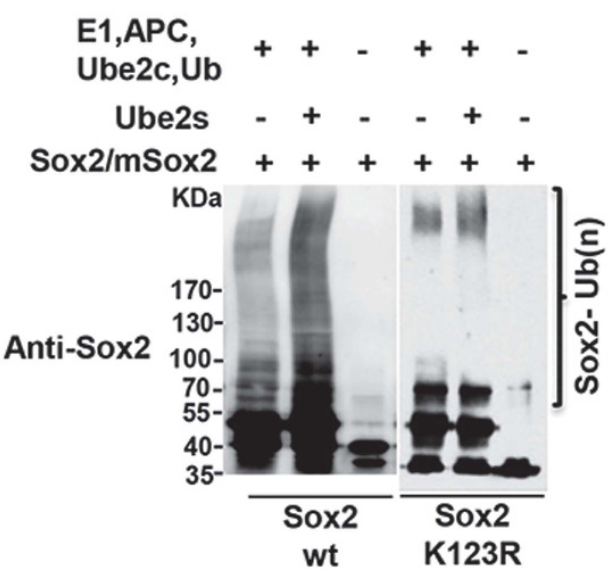


by Ube2s can be reversed by expressing the Sox $2-\mathrm{K} 123 \mathrm{R}$ mutant, indicating that Ube2s regulates Esrrb through ubiquitinating Sox2 (Supplementary Figure S9).

To further characterize the functional relevance of Esrrb induction in Ube2s-overexpressed ES cells, we treated these cells with LIF withdrawal. Previous studies show that Esrrb can replace Nanog to confer ES cells' resistance to LIF withdrawal. ${ }^{31,32}$ Indeed, Ube2s-overexpressed cells sustain relatively high expression levels of stemness-related genes and positive AP staining signal under LIF withdrawal (Supplementary Figure S10). Moreover, these cells also display resistance to $\mathrm{RA}$ treatment-induced differentiation (Figures $5 \mathrm{e}$ and $\mathrm{f}$ ). To further clarify whether Esrrb is a downstream effector to confer Ube2s-overexpressed mES cell resistance to differentiation, we treated these cells with diethylstilbestrol (DES) that functions as an estrogen-related receptor antagonist to inhibit Esrrb transcriptional activity. ${ }^{33}$ Strikingly, upon adding DES to the RA-containing medium, both red AP staining signals and the expression of selfrenewal genes are reduced in Ube2s-overexpressed mES cells, suggesting that these cells could not resist RA-induced differentiation (Figures $5 \mathrm{~g}$ and $\mathrm{h}$ ). These results collectively demonstrate that Ube2s reinforces the undifferentiated state of mES cells through inducing Esrrb.

Next, we established ES cell lines stably overexpressing Ube2s and selected two such lines (U1 and U2) that exhibit expression profiles of marker genes similar to the transient Ube2s-expressed ES cells (Figure 5a and Supplementary Figure S11). A teratoma formation assay reveals that both lines are capable of forming all germ layer cell lineages including endoderm, mesoderm and ectoderm, demonstrating their pluripotency (Figure 6). These data imply that elevated Ube2s, despite its role in reducing cellular Sox2, sustains ES cells in an undifferentiated self-renewing and pluripotent state. In fact, this observation appears to support recent reports highlighting the importance of Esrrb in establishing pluripotency and self-renewal independent of Sox2. ${ }^{34-36}$ Buganim et al. ${ }^{34}$ reported that combination of Esrrb, Nanog, Sall4 and Lin28 can efficiently support pluripotency with a quality higher than other factor combinations, including Oct4, Sox2, KIf4 and Myc. $^{34}$ Interestingly, in addition to Esrrb and Nanog, the expression levels of Lin28 and Sall4 also maintain at a higher expression level in U1 and U2 cells (Figure 6b). Their induced expression may compensate for the reduced Sox2 to maintain the pluripotency of Ube2s-overexpressed ES cells.

\section{Discussion}

As a core regulator of the ES cell networks, Sox2 attracts particular attention because of its critical role in ES cell maintenance and the derivation of induced pluripotent stem cell generation. ${ }^{17,37}$ However, the function of Sox2 is not restricted to ES cells. Rather, it is involved in a variety of fetal and adult stem cells, such as neural stem cells, retina and pituitary progenitor cells. ${ }^{38-41}$ At the molecular level, Sox2 serves as a pioneer factor and is involved in cell fate determination through its dynamic interactions with different protein partners for transcriptional regulation of corresponding sets of target genes. ${ }^{42-45}$ For example, in undifferentiated ES cells, Sox2 forms a heterodimer with Oct4 to activate stemness-related genes while repressing differentiationspecific genes. $^{2,25}$ Upon ES cell differentiation, their interaction is disturbed. Instead, Sox2 coordinates other proteins, such as PARylated Parp1, which prevents its binding with the Oct-Sox target DNA sequence and in turn regulates distinct sets of genes. ${ }^{46}$ For example, during lens ectoderm cell lineage specification, Sox2 interacts with Pax6 to regulate lens-specific genes. ${ }^{43}$ In trophoblast stem cells, Sox2 cooperates with Tfap2c to orchestrate the unique transcription profiles underpinning the corresponding functional properties of these cells. ${ }^{47}$ Of note, the role of Sox2 is highly dosagedependent. ${ }^{4,44}$ In ES cells, both elevation and depletion of Sox2 results in cell differentiation. ${ }^{3-5}$ Hence, controlled regulation of Sox2 expression to fine-tune its level becomes critical for the maintenance of ES cells and cell lineage commitment.

Thus far, extensive studies have well documented how Sox2 is genetically and epigenetically regulated at the transcriptional level. ${ }^{2,3,25,48-50}$ However, knowledge regarding the precise mechanisms underlying how Sox2 is posttranslationally regulated remains limited. Several studies have shown that the protein activity of Sox2 can be modified by sumoylation, methylation, acetylation and phosphorylation. These modifications influence its subcellular distribution, protein stability or DNA-binding activity, and subsequently remodel its transcriptional activity towards downstream target genes. ${ }^{51-53}$ For instance, AKT1 mediates Sox2 phosphorylation at its $\mathrm{T} 118$ residue, resulting in increased Sox 2 stability and thus ensuring its high protein level in ES cells. ${ }^{52}$ On the contrary, acetyltransferase p300 is capable of acetylating Sox2, which is provided as a nuclear export signal and destines Sox 2 for ubiquitination and degradation. ${ }^{51}$ Obviously, these studies documented regulation of Sox2 stability by ubiquitination; however, the delicate mechanisms mediating this process remain to be illustrated. Interestingly, in this study we detected a robust direct association between E2 Ube2s and Sox2 substrate. Recently, two studies dissected the detailed mechanism used by Ube2s and its E3 APC to drive polyubiquitin chain formation on substrates. ${ }^{54,55}$ In their model, APC simultaneously associates with Ube2s and substrate, and continuously adds $\mathrm{Ub}$ to the distal end of the growing polyubiquitin chain in a one-by-one manner.

Figure 3 Ube2s represses the biological function of Sox2. (a) Ube2s represses the activity of Sox2 in regulating Nanog transcription, as shown by a luciferase reporter assay. The data are normalized to the activity of the cells transfected with empty vectors (CK) and presented as the mean \pm S.D. $\left(t\right.$-test; $\left.{ }^{* \star \star} P<0.005 ;{ }^{* *} P<0.01\right)$. The expression levels of Ube2s/mUbe2s and Sox2 were monitored by western blot with antibodies against Flag and HA, respectively. (b) Ube2s repressed Sox2-enhanced ES cell differentiation. mES cells were co-transfected with the two constructs overexpressing Sox2 and Ube2s or mUbe2s. Empty vector transfection (CK) and single overexpression (OE) of Sox2, Ube2s or mUbe2s were used as controls. Twenty four hours after transfection, the cells were induced to differentiate into neuroectoderm. The resulting cells were analyzed by immunocytochemistry staining assay with antibodies against Ube2s, Sox2, $\beta$ III-tubulin, Sox1 and DAPI (4',6-diamidino-2-phenylindole). Photographs were taken with x200 magnification. Scale bars represent $50 \mu \mathrm{m}$. (c) The resulting cells of (b) were analyzed by qRT-PCR. The data are based on three independent experiments 
a

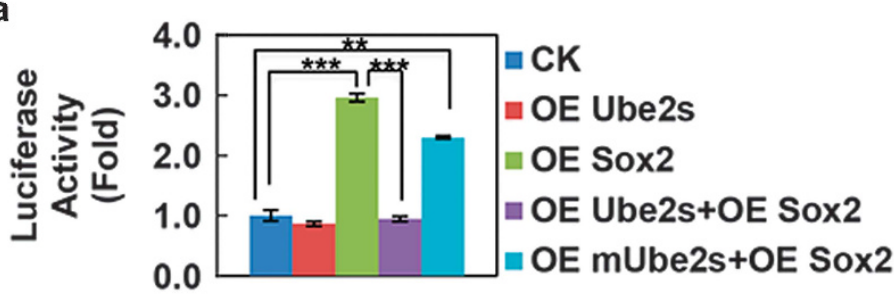

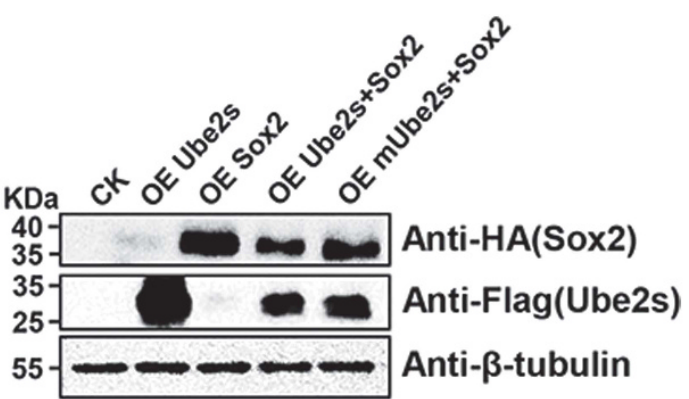

b
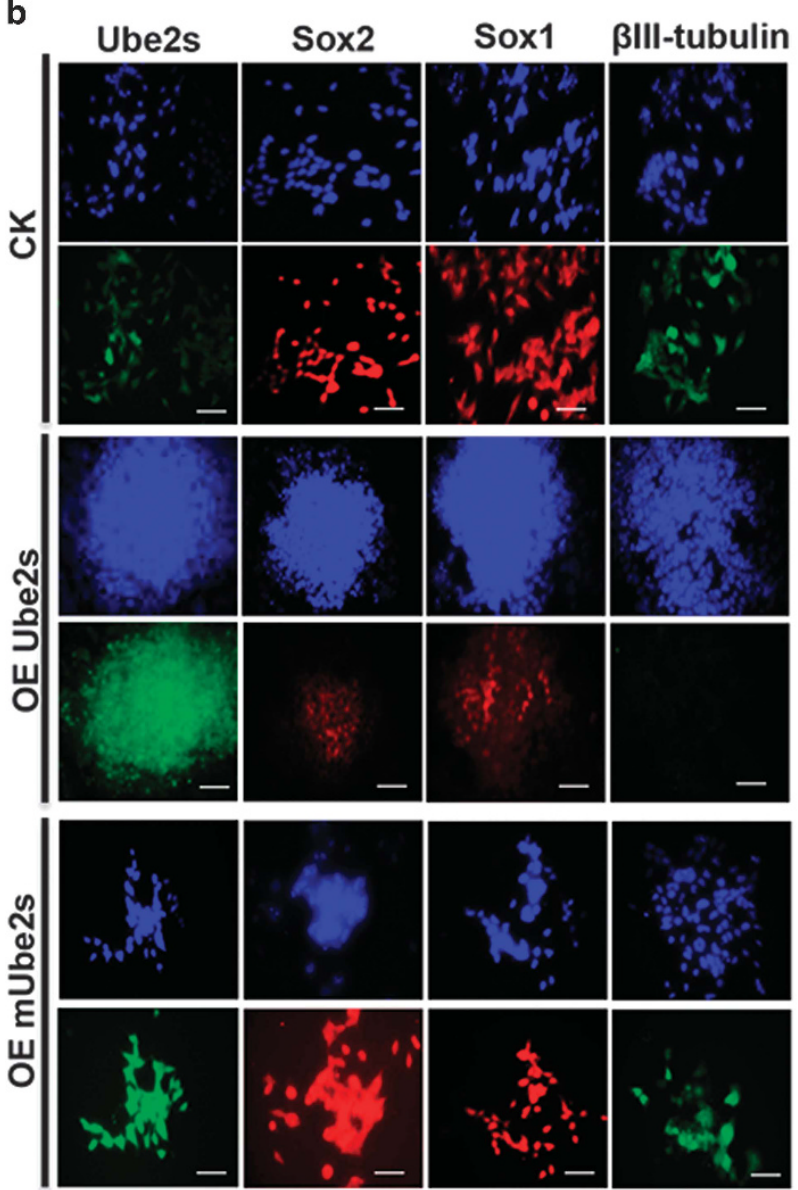
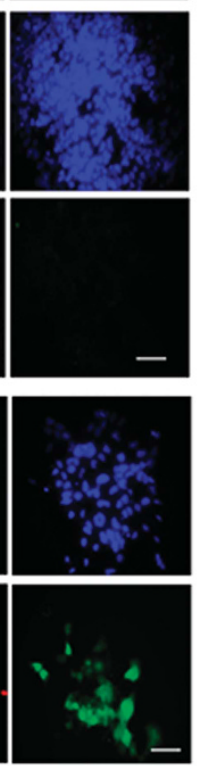

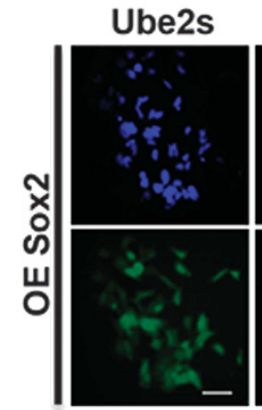

Sox2
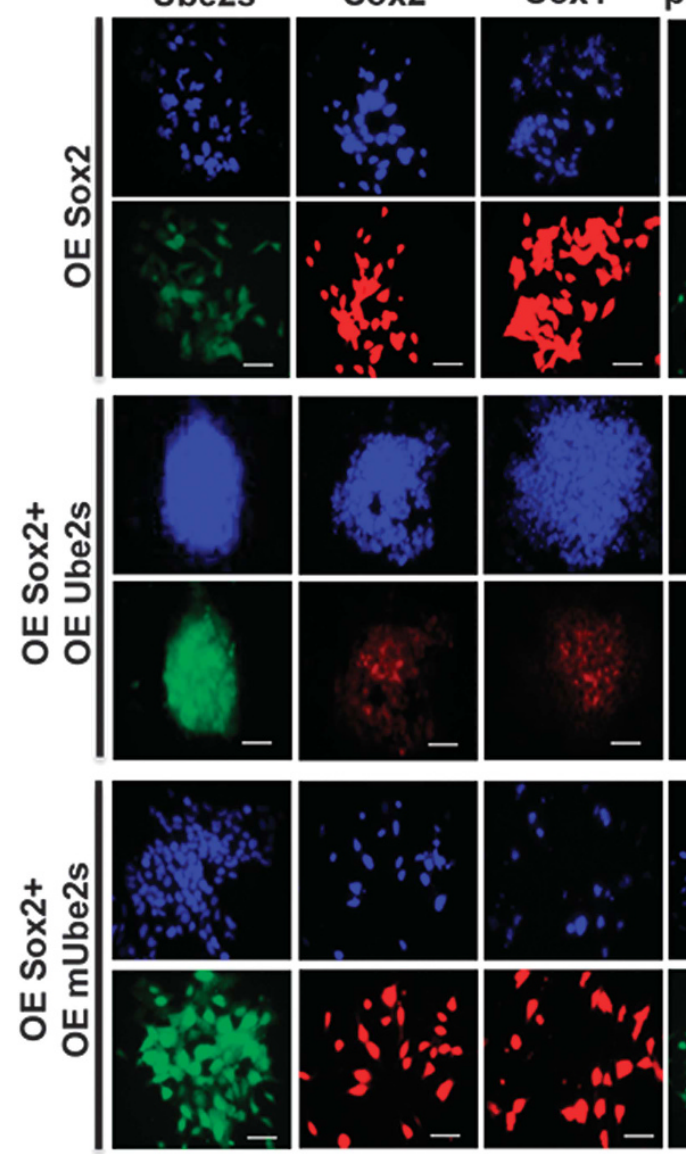

Blll-tubulin
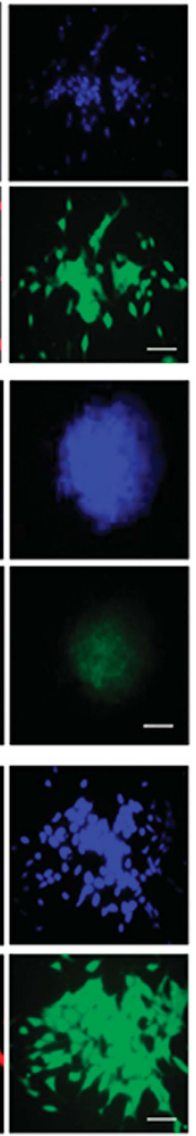

C

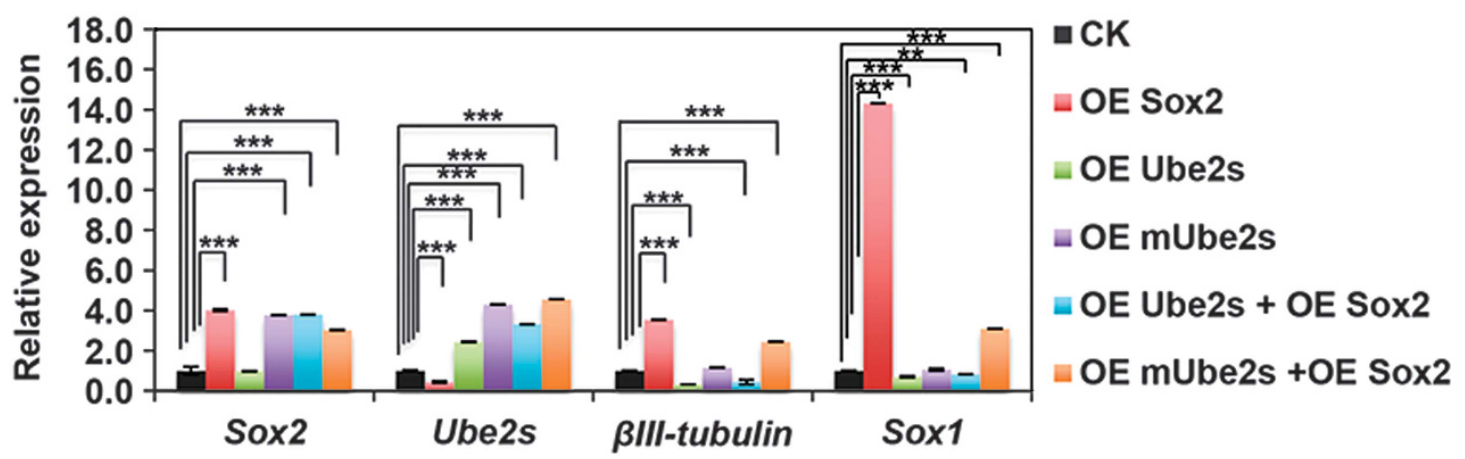


We speculate that the high affinity between Ube2s and Sox2 may enhance the efficiency of polyubiquitin chain formation on Sox2.

Several studies have shown that ubiquitination is involved in regulating ES cell maintenance. For example, the study by Liao et al. ${ }^{56}$ demonstrates that Wwp2 can mediate ubiquitination of Oct4 by forming a K63-linked Ub chain to promote its degradation. ${ }^{56}$ Moreover, phosphorylated c-Myc on Thr58 by Gsk3 can be targeted by $\mathrm{SCF}^{\mathrm{fbxw} 7}$ for ubiquitination and proteasomal degradation, which results in differentiation of ES cells. ${ }^{57,58}$ Interestingly, a recent study by Fang et al. ${ }^{7}$ demonstrates that an E3, Wwp2, specifically identifies monomethylated Sox2 at K119 and promotes its ubiquitination. In this study, we identified Ube2s as a novel key ES cell regulator. It directly interacts with Sox 2 to fine-tune the protein level of Sox2 through K11-linked polyubiquitination at the Sox $2-\mathrm{K} 123$ residue, and thus reinforces the undifferentiated state of ES cells. Interestingly, the importance of the interaction extends to the role of Ube2s in regulating ES cell differentiation to the neural ectoderm lineage. As Sox2 is important for neurogenesis in the adult central nerve system through its maintenance of neural stem and progenitor cells, ${ }^{17-19}$ as a regulator of Sox2 ubiquitination, Ube2s may have yet unexplored role in regulating neurogenesis, and its dysfunction may be related to neurodegenerative diseases.

\footnotetext{
Materials and Methods

Cell culture. Mouse E14 ES cells (ATCC, Manassas, VA, USA) were cultured under a feeder-free condition at $37^{\circ} \mathrm{C}$ with $5 \% \mathrm{CO}_{2}$. The cells were maintained on gelatin-coated dishes in Dulbecco's modified Eagle's medium (DMEM; Gibco, Grandlsland, NY, USA), supplemented with $15 \%$ heat-inactivated fetal bovine serum (FBS; Gibco), $0.1 \mathrm{mM} \beta$-mercaptoethanol (Gibco), $2 \mathrm{mM}$ L-glutamine, $0.1 \mathrm{~mm}$ MEM nonessential amino acid, $5000 \mathrm{U} / \mathrm{ml}$ penicillin/streptomycin and $1000 \mathrm{U} / \mathrm{ml}$ of LIF (ESGRO, Millipore, Billerica, MA, USA; ESG1107).

Plasmids and cell transfection. Sox2 and Ube2s ORFs were inserted into vectors $\mathrm{pCAG}-3 \mathrm{xHA}$ and $\mathrm{pCAG}-3 \mathrm{xFlag}$, respectively, for overexpression. Nineteen base pair (bp) gene-specific oligonucleotides for RNA interference were designed with the criteria defined by the work of Reynolds et $a l^{59}$ and Ui-Tei et al. ${ }^{60}$ The RNAi oligonucleotides were cloned into pSuperpuro (Oligoengine, Seattle, WA, USA) between Bgll and Hindlll sites, and 19-bp short hairpin RNAs (shRNAs) with a 9-bp loop were expressed by the pSuperpuro plasmids. The two target sequences of the Ube2s shRNAs are $5^{\prime}$-GCTACTTCCTGACTAAAAT-3' and 5'-GGAGGTCTGT TCCGTATGA-3'. Transfection of shRNA and overexpression plasmids was performed using Lipofectamine 2000 (Invitrogen, Grand Island, NY, USA; 11668019). To establish the Ube2s overexpression cell lines, $2 \mu \mathrm{g}$ of pCAG-3xHA containing the Ube2s ORF were transfected into ES cells on $60 \mathrm{~mm}$ plates. After 1-week selection with puromycin $(1 \mu \mathrm{g} / \mathrm{ml}), 10$ colonies were picked. The expression level of Ube2s was checked in a western blot using antibodies against HA. Empty pCAG-3xHA was used as a control.
}

Protein purification. The recombinant GST-tagged proteins were expressed in BL21 after induction with $0.2 \mathrm{mM} \mathrm{IPTG}$ at $16^{\circ} \mathrm{C}$ and conjugated to glutathionesepharose beads (GE Healthcare, Pittsburg, PA, USA) in a lysis buffer (50 mM Tris (pH 8.0), 10\% glycerol, $0.3 \mathrm{M} \mathrm{NaCl}, 2 \mathrm{mM}$ EDTA, $0.1 \%$ Triton X-100, $3 \mathrm{mM}$ DTT, $1 \mathrm{~mm}$ PMSF, $1 \%$ protease inhibitor cocktail). After a $1.5 \mathrm{~h}$ incubation at $4{ }^{\circ} \mathrm{C}$, the supernatant was removed with a 5 min spin at 1000 r.p.m., and the beads were washed two times with the lysis buffer at $4^{\circ} \mathrm{C}$. The recombinant GST-tagged proteins were eluted from the beads with the elution buffer (50 mM Tris $(\mathrm{pH} \mathrm{8.0)}$ ), $10 \%$ glycerol, $0.3 \mathrm{M} \mathrm{NaCl}, 0.1 \%$ Triton X-100, $0.5 \mathrm{mM} \mathrm{PMSF}, 10 \mathrm{mM} \beta$ mercaptoethanol, $15 \mathrm{mM} \mathrm{GSH}$ ).

The recombinant $6 x$ His-tagged proteins were expressed in BL21 after induction with $0.2 \mathrm{mM} \mathrm{IPTG}$ at $16^{\circ} \mathrm{C}$ and conjugated to Ni superflow beads in wash buffer (20 mM HEPES (pH 7.5), 10\% glycerol, $1 \mathrm{~m} \mathrm{NaCl,} \mathrm{0.2 \%} \mathrm{Triton} \mathrm{X-100,} 25 \mathrm{mM}$ imidazole, $10 \mathrm{mM} \beta$-mercaptoethanol, $0.5 \mathrm{~mm}$ PMSF, 1\% protease inhibitor cocktail). The beads were washed five times at $4{ }^{\circ} \mathrm{C}$, and the recombinant $6 x$ His-tagged proteins were then eluted from the beads with the elution buffer $(20 \mathrm{~mm}$ HEPES (pH 7.5), $10 \%$ glycerol, $0.3 \mathrm{~m} \mathrm{NaCl}, 0.35 \mathrm{~m}$ imidazole, $0.1 \%$ Triton $\mathrm{X}-100,10 \mathrm{~mm}$ $\beta$-mercaptoethanol, $0.5 \mathrm{mM}$ PMSF, $1 \%$ protease inhibitor cocktail).

RNA isolation, reverse transcription and qRT-PCR analysis. Total RNAs were extracted using Trizol (Invitrogen; 15596018). cDNA synthesis was performed with $500 \mathrm{ng}$ of total RNA using TransScript All-in-One First-Strand cDNA Synthesis SuperMix (TransGen, Beijing, China; AT341-01) according to the manufacturer's instructions. mRNA levels were measured by quantitative real-time RT-PCR (qRT-PCR) analysis based on SYBR Premix Ex Taq (Takara, Shiga, Japan; RR420A) with the Bio-Rad real-time PCR machine (Bio-Rad, Hercules, CA, USA). Results were normalized to $\beta$-actin. All the primers used in the study give rise to single product with the right size in agarose gel analysis. The data are presented as the mean \pm S.D. $\left(\right.$ t-test; $\left.{ }^{* * *} P<0.005 ;{ }^{* *} P<0.01 ;{ }^{*} P<0.05\right)$.

Protein extraction and western blotting. Total protein was extracted by lysing cells with the whole-cell extraction buffer (50 mM Tris; $150 \mathrm{mM} \mathrm{NaCl} ; 1 \%$ NP-40; $10 \%$ glycerol; $1 \mathrm{~mm}$ EDTA; $1 \mathrm{mM} \mathrm{PMSF).} \mathrm{Fifty} \mathrm{micrograms} \mathrm{of} \mathrm{the} \mathrm{total}$ proteins were separated by SDS-PAGE and transferred to PVDF membrane. The membrane was blocked with $5 \%$ milk and probed with specific primary and secondary antibodies. The blots were developed with ECL Advance Western Blotting Detection Kit (Amersham, Uppsala, Sweden; no. 34080). The antibodies used in this study include anti-Sox2 (Abcam, Cambridge, MA, USA; ab59776), antiUbe2s (Cell Signaling; no. 9630s), anti-Cdh1 (Santa Cruz; sc-56312), anti-Cdc20 (Abcam; ab32384), anti-Cdc27 (Santa Cruz; sc-5618), anti-Oct4 (Santa Cruz; sc8628), anti-HA (Santa Cruz; sc-7392), anti-Flag M2 (Sigma, St. Louis, MO, USA; F1804), anti-GST (Santa Cruz; sc-138), anti-Apc10 (Novus Biologicals, Littleton, CO, USA; NB600887), anti- $\beta$-tubulin (Santa Cruz; sc-166729) and anti- $\beta$-actin (Boster, Wuhan, China; BM0627).

Immunoprecipitation. Five hundred micrograms of protein samples in a total volume of $500 \mu \mathrm{l}$ reaction solution were immunoprecipitated with $2 \mu \mathrm{g}$ of antibody and $20 \mu \mathrm{l}$ of Protein-G beads (GE Healthcare; 17-0618-01). The samples were rotated at $4^{\circ} \mathrm{C}$ overnight. The beads were washed four times with $1 \mathrm{ml}$ of cold NP-40 lysis buffer containing protease inhibitors (Roche; 04693132001). The beads were then boiled for $10 \mathrm{~min}$ in the presence of $20 \mu \mathrm{l} 2 \mathrm{x}$ sample buffer and the eluted proteins were fractionated by SDS-PAGE in 12 or $15 \%$ gels. Proteins were detected by immunoblotting as described above.

GST pull-down assay. Purified GST-tagged protein were precleared with glutathione-sepharose 4B (GE Healthcare; 17-0756-01) for $1.5 \mathrm{~h}$ and incubated with

Figure 4 Ube2s is indispensible for mES cell maintenance. (a) Ube2s was depleted in mES cells. The construct expressing Ube2s shRNA was transfected into mES cells. After a 3-day antibiotic selection, the cells were stained for AP (upper panel). Photographs were taken with $\times 40$ magnification. The mRNA level of Ube2s was monitored by qRTPCR. The protein levels of Ube2s and Sox2 were analyzed by western blotting (lower panel) (b) qRT-PCR analyses of selected marker genes in Ube2s-depleted mES cells. (Upper panel) Self-renewal marker genes and (lower panel) differentiation-related marker genes. (c) Cell-replating assay to characterize Ube2s-depleted mES cells. The cells were stained with Coomassie blue (upper panel). The lower panel represents the total number of colonies formed. (d) mES cells were transfected with $4 \mu \mathrm{g}$ constructs for Ube2s overexpression (OE) on 6-cm culturing plates. After a 3-day antibiotic selection, cells were analyzed using an AP staining assay. Photographs were taken with $\mathrm{x} 100 \mathrm{magnification}$. The expression level of Ube2s was monitored by western blotting and qRT-PCR. (e) The Ube2s-overexpressed mES cells were assessed by the cell replating assay. Experimental procedure was as described in (c). The data are based on three independent experiments. Scale bars in (a, $\mathbf{c}$ and e) represent $250 \mu \mathrm{m}$. Scale bars in (d) represent $100 \mu \mathrm{m}$. $\mathrm{CK}$, empty vector transfection control 
His-tagged fusion proteins at $4{ }^{\circ} \mathrm{C}$ overnight. Protein-bound sepharose beads were washed four times with lysis buffer and eluted in SDS-PAGE sample buffer. Eluted proteins were analyzed by immunoblotting.

Immunocytochemistry. mES cells were fixed with $4 \%$ formaldehyde for $30 \mathrm{~min}$ and washed four times with PBST buffer ( $0.25 \mathrm{~g}$ Tween-20 dissolved in PBS solution).
Subsequently, the cells were blocked with $5 \%$ horse serum diluted in PBST buffer. Primary antibodies were applied in blocking solution at $4{ }^{\circ} \mathrm{C}$ overnight. The primary antibodies used in this study include anti-Sox2 (Abcam; ab59776, 1: 400), anti-Ube2s (Santa Cruz; sc-131354, 1:50), anti-Sox1 (Abcam; ab22572, 1:50) and anti- $\beta \| 11-$ tubulin (Millipore; MAB1637; 1:50). After washing with PBST buffer, the coverslips were incubated with Alexa546-conjugated anti-rabbit (Molecular Probes; $1: 3000$ ) and
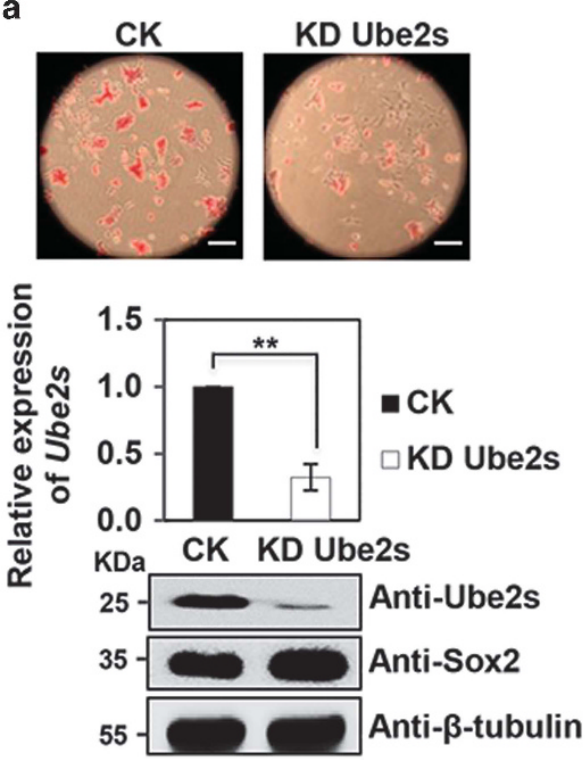

c
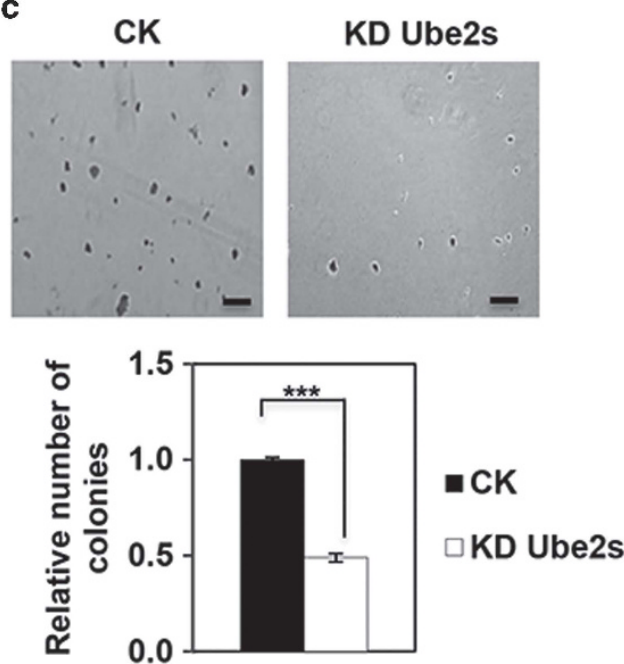

b
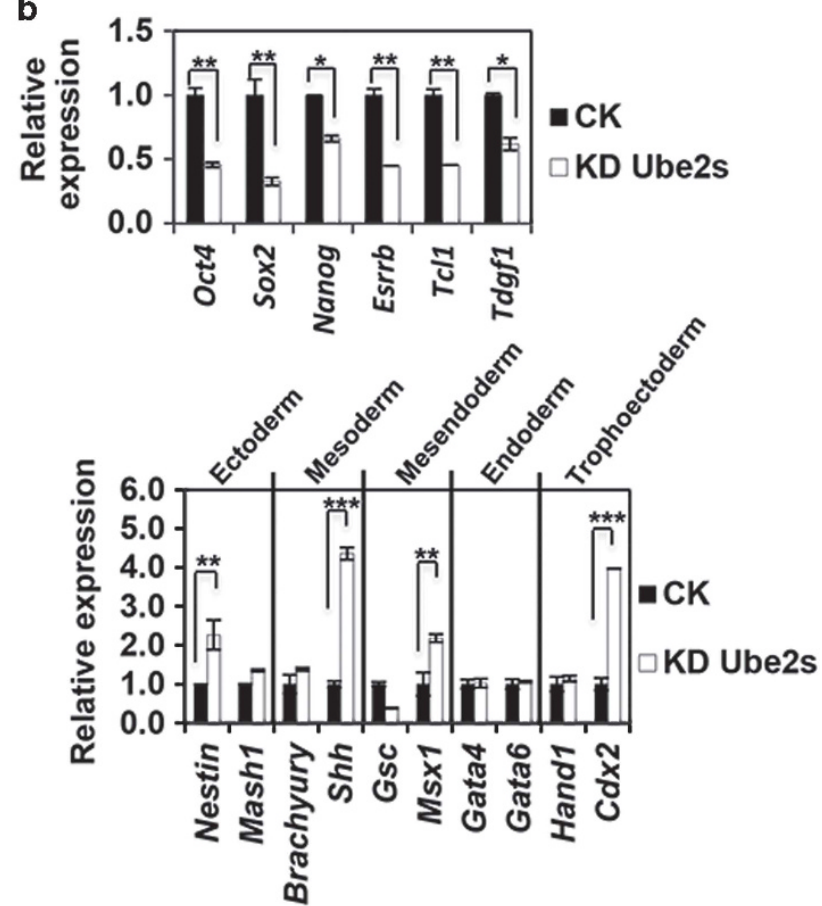

d
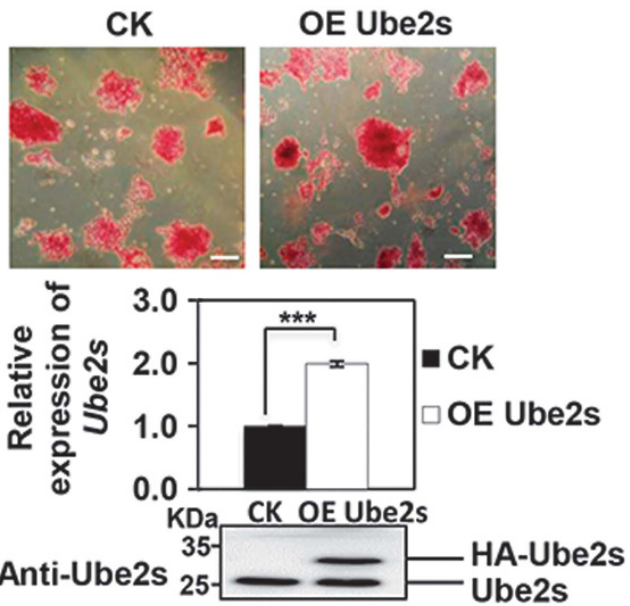

Anti- $\beta$-tubulin 55

e
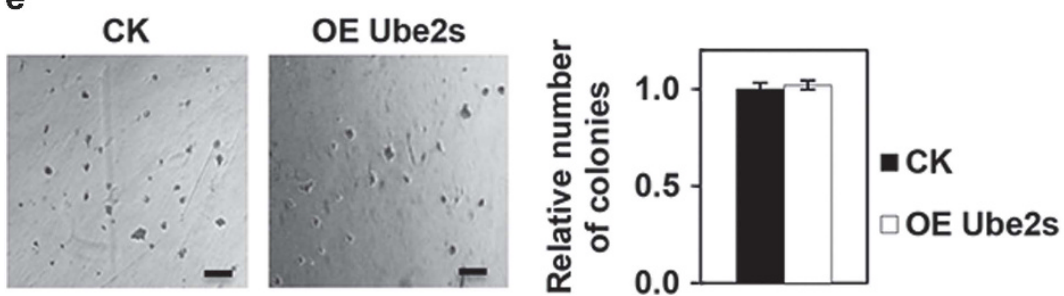


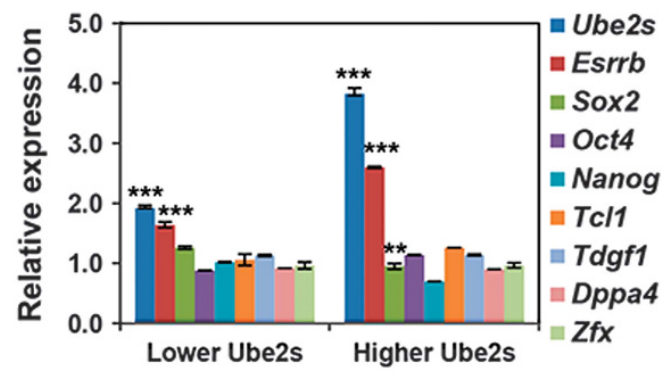

C

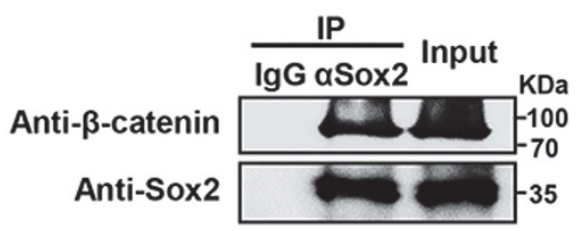

e

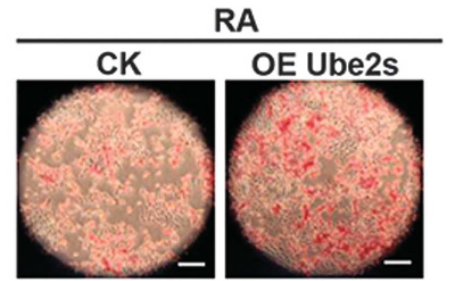

g

No RA RA+DES treatment treatment treatment

CK
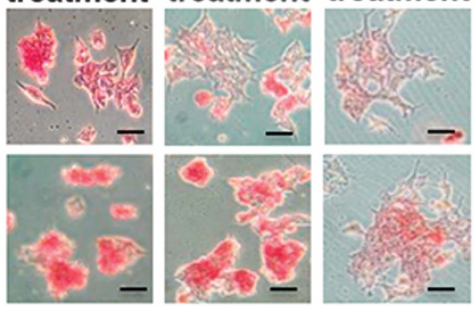

d

f

h b
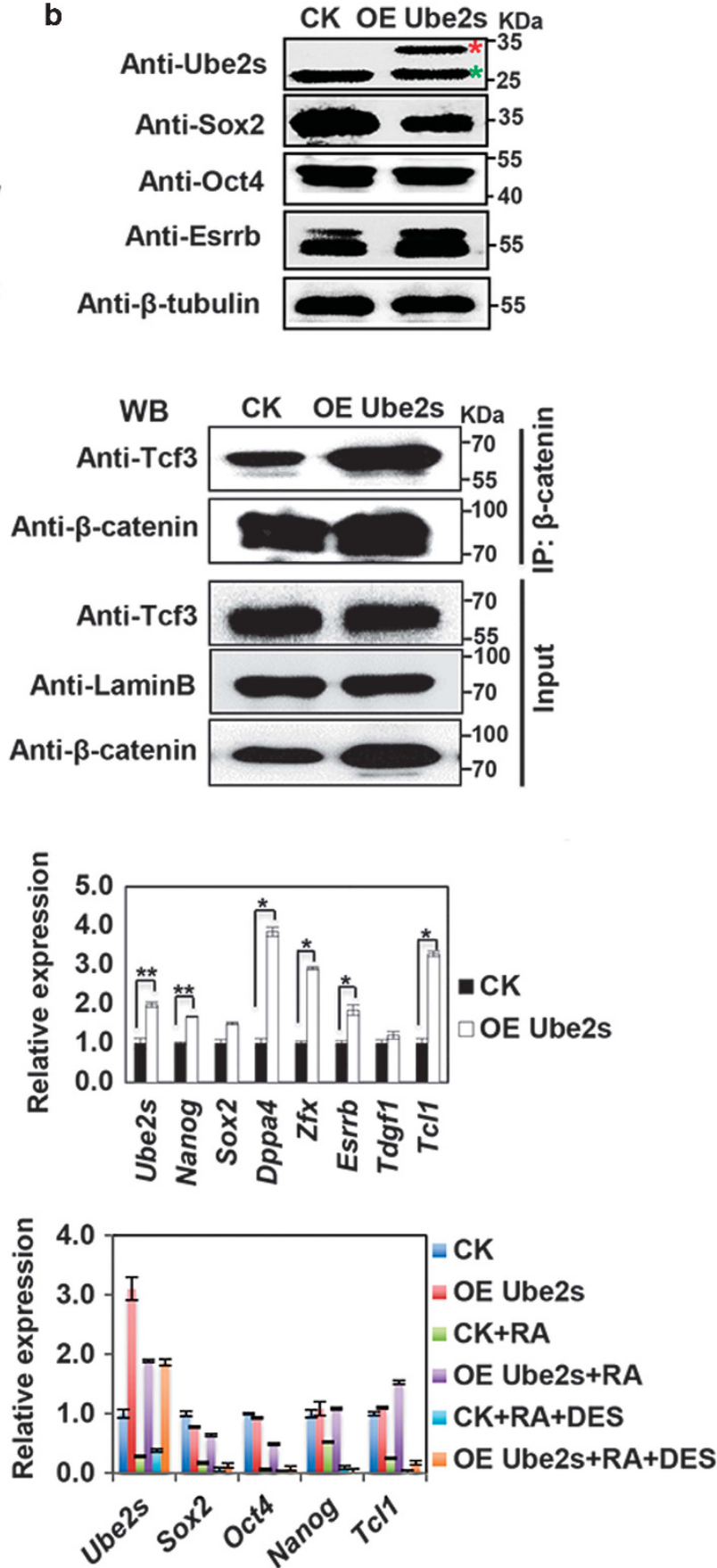

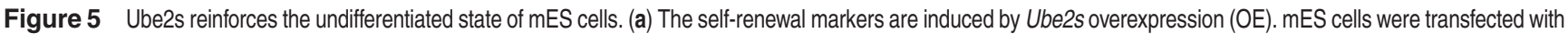
$2 \mu \mathrm{g}$ (for lower OE of Ube2s) and $4 \mu \mathrm{g}$ (for higher OE of Ube2s) constructs overexpressing Ube2s on 6-cm culturing plates. After a 3-day antibiotic selection, the cells were harvested for qRT-PCR analysis of self-renewal markers. The data are normalized to vector transfection control. (b) Western blotting to monitor the protein level changes of Sox2, Oct4 and Esrrb in the cells with lower OE of Ube2s. $\beta$-Tubulin serves as a loading control. Red asterisk: Ube2s fused with the HA tag; green asterisk: endogenous Ube2s. (c) Co-IP to detect the association of Sox2 with $\beta$-catenin. mES cell extracts were subjected to co-IP with an anti-Sox2 antibody or IgG, followed by western blotting with Sox2 and $\beta$-catenin antibodies. (d) Co-IP to detect the association of Tcf3 with $\beta$-catenin. The nuclear extracts of Ube2s-overexpressed ES and vector-transfected cells (CK) were subjected to co-IP with an anti- $\beta$-catenin antibody, followed by western blotting with Tcf3 and $\beta$-catenin antibodies. The nuclear extract input sample was monitored by western blotting. (e) Ube2s elevation conferred $\mathrm{mES}$ cell resistance to RA-induced differentiation. Ube2s overexpressing mES and vector-transfected control cells (CK) were grown in the presence of $0.5 \mu \mathrm{M}$ RA for $24 \mathrm{~h}$. Subsequently, the cells were analyzed using an AP staining assay. Photographs were taken with $x 40$ magnification. Scale bars represent $250 \mu \mathrm{m}$. (f) The resulting cells in (e) were analyzed by qRT-PCR. ( $\mathbf{g}$ and $\mathbf{h}$ ) DES treatment compromises the differentiation of Ube2s-overexpressed $\mathrm{mES}$ cells. Ube2s-overexpressed and vector-transfected (CK) mES cells were treated with $500 \mathrm{nM}$ RA and $12.5 \mu \mathrm{M}$ DES (dissolved in dimethyl sulfoxide (DMSO)) for $24 \mathrm{~h}$. The resulting cells were analyzed using an AP staining assay (g) and gRT-PCR (h). Photographs were taken with $\times 100$ magnification. Scale bars in $(\mathbf{g})$ represent $100 \mu \mathrm{m}$. The changes for the qRT-PCR analysis are normalized to the CK control. The data presented are based on three independent samples 


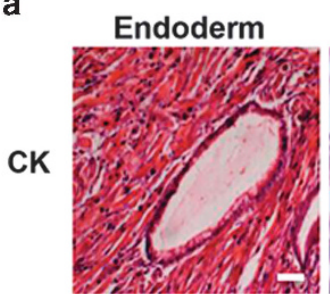
Gut-like epithelium

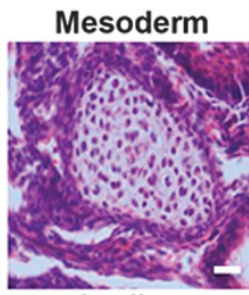

Cartilage

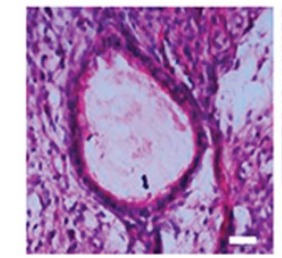

Gut-like epithelium

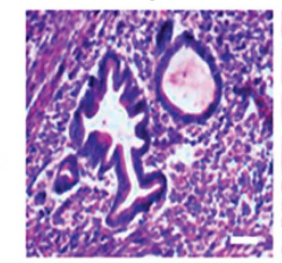

Gut-like epithelium

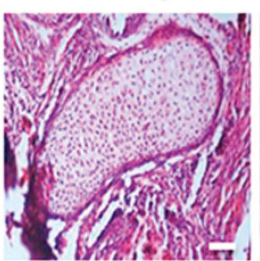

Cartilage

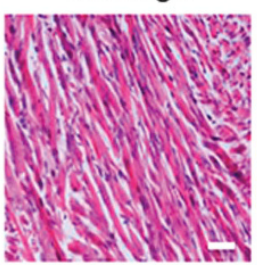

Muscle

b

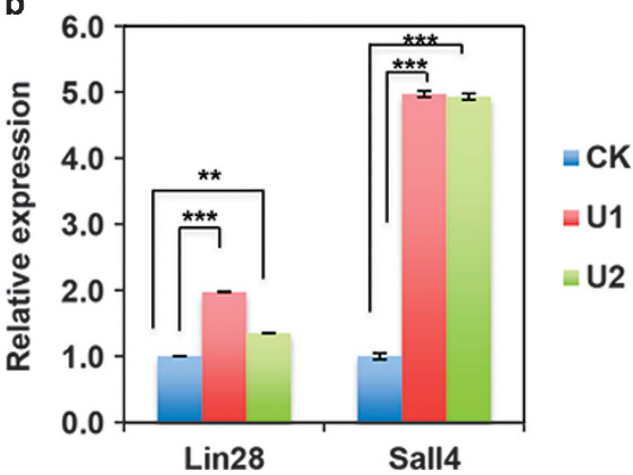

Figure 6 Ube2s OE stable ES cell lines maintain pluripotency. (a) Hematoxylin and eosin (HE) staining of teratoma sections generated from Ube2s stably transfected ES cell lines, U1 and U2. CK, vector-transfected stable cell line. Scale bars represent $250 \mu \mathrm{m}$. (b) Total RNAs of U1, U2 and control cell line (CK) were extracted for qRT-PCR analysis of the expression of Lin28 and Sall4. The data are based on three independent samples

Alexa488-conjugated anti-goat (Molecular Probes; $1: 2000$ ) secondary antibodies for $20 \mathrm{~min}$. The secondary antibody solution also contained $2 \mu \mathrm{g} / \mathrm{ml} \mathrm{DAPI}$. After washing with PBST buffer three times, the cell images were captured. All red and green images were adjusted identically to generate the merge images.

To detect Ube2s foci formation with Sox2 on chromatin, the cells were seeded onto poly-lysine-coated coverslips and rinsed with ice-cold PBS. Before formaldehyde fixation, we treated the cells with $0.4 \% \mathrm{NP}-40$ in PBS for 40 min on ice. The remaining experimental procedure was the same as the immunocytochemical staining assay.

In vitro ubiquitination assay. A $0.5 \mathrm{ml}$ conjugation reaction containing $300 \mathrm{~nm}$ E1 (Uba1), $600 \mu \mathrm{M}$ Ub, $500 \mathrm{~nm}$ Ube2s, $500 \mathrm{nM}$ Ube2c, $5 \mu \mathrm{l} \mathrm{Apc} \mathrm{Adc}^{27}$ complex solution and $200 \mathrm{nM}$ Sox2 in an ATP cocktail (10 mM HEPES, pH 7.5; $5 \mathrm{mM} \mathrm{MgCl} 2 ; 5 \mathrm{mM} \mathrm{ATP} ; 0.6 \mathrm{U} / \mathrm{ml}$ inorganic phosphatase) was incubated at $30^{\circ} \mathrm{C}$ for $90 \mathrm{~min}$. Reactions were terminated by the addition of trichloroacetic acid (final concentration of $10 \%$ ), and subsequently analyzed by SDS-PAGE and western blotting with the antibody against Sox2 (Santa Cruz; sc-17320).
Luciferase reporter assay. HEK-293 cells were seeded in 24-well plates at a density of $1 \times 10^{5}$. After $24 \mathrm{~h}$, the cells were transfected using Lipofectamine 2000 (Invitrogen). Briefly, the promoter region of Nanog targeted by Sox2 was cloned into the pGL4.2-Luc vector, and subsequently co-transfected with pCAGpuro-Sox2-3xHA and pCAGhygro-Ube2s-3xFlag or pCAGhygro-mUbe2s-3xFlag plasmids, together with the pRL-SV40 Renilla luciferase construct. Single overexpression of either Ube2s or Sox2 and mock pCAG vectors (vector transfection control (CK)) were used as controls. Cell extracts were prepared $48 \mathrm{~h}$ after transfection and the luciferase activity was measured by using the Dual Luciferase System (Promega, Madison, WI, USA) and a Centro LB960 96-well luminometer (Berthold Technologies, Bad Wildbad, Germany)

Neuroectoderm differentiation assay. Neuroectoderm differentiation assay was performed as described previously by Thomson et al. ${ }^{26}$ Briefly, mES cell medium was changed to fresh N2B27 medium. After $48 \mathrm{~h}$ of culturing, $800 \mathrm{nM}$ RA was added to treat the cells for 2 days. The resulting cells were analyzed by immunocytochemistry staining or western blotting assays.

Cell-replating assay. The construct expressing Ube2s shRNA was transfected into mES cells. After 2-day antibiotic selection, the cells were reseeded in a 6 -well plate at a density of $3 \times 10^{5}$ cells per well. The cells were analyzed on the seventh day after seeding.

Teratoma formation assay. The experimental mouse work followed the animal care protocol LA2013-1 approved by Peking University Animal Research Ethics Board and was conducted at the Peking University Health Science Center, China. For the teratoma formation assay, $5 \times 10^{6}$ cells from the Ube2soverexpressed ES lines, U1 and U2, and control cell lines were injected subcutaneously into the lateral flanks of 5-week-old SCID female nude mice. Six mice were used for every cell line. The mice were killed 5 weeks after cell injection. Formalin-fixed teratoma isolated were paraffin-embedded, and tissue sections were stained with hematoxylin and eosin staining to evaluate the cellular morphology.

\section{Conflict of Interest}

The authors declare no conflict of interest.

Acknowledgements. This work was supported by NSFC fund (31101055), Beijing Training Program Foundation For Excellent Talents (2012D005016000009) and Scientific Research Foundation for the Returned Overseas Chinese Scholars from the Education Ministry of China (2011-1568). We thank Michelle Hanna for critical comments on the manuscript.

\section{Author contributions}

JJW and YRZ: conception and design, collection and/or assembly of data, data analysis and interpretation, administrative support and final approval of manuscript; $\mathrm{JH}, \mathrm{XHQ}, \mathrm{HZ}$, ZLZ, MYL, RFW and KPL: collection and/or assembly of data, data analysis and interpretation, and final approval of manuscript; YW, ZYL, DZ, PW, LD and FYL: collection and/or assembly of data and final approval of manuscript; XMW and YW: conception and design, data analysis and interpretation, and final approval of manuscript; WX: conception and design, financial support and final approval of manuscript; WWZ: conception and design, data analysis and interpretation, financial support, administrative support, final approval of manuscript and manuscript writing.

1. Smith AG. Embryo-derived stem cells: of mice and men. Annu Rev Cell Dev Biol 2001; 17 435-462.

2. Chen $X, X u H$, Yuan $P$, Fang F, Huss $M$, Vega VB et al. Integration of external signaling pathways with the core transcriptional network in embryonic stem cells. Cell 2008; 133: 1106-1117.

3. Chew JL, Loh YH, Zhang W, Chen X, Tam WL, Yeap LS et al. Reciprocal transcriptional regulation of Pou5f1 and Sox2 via the Oct4/Sox2 complex in embryonic stem cells. Mol Cell Biol 2005; 25: 6031-6046.

4. Kopp JL, Ormsbee BD, Desler M, Rizzino A. Small increases in the level of Sox2 trigger the differentiation of mouse embryonic stem cells. Stem Cells 2008; 26: 903-911.

5. Li J, Pan G, Cui K, Liu Y, Xu S, Pei D. A dominant-negative form of mouse SOX2 induces trophectoderm differentiation and progressive polyploidy in mouse embryonic stem cells. J Biol Chem 2007; 282: 19481-19492.

6. Kim J, Chu J, Shen X, Wang J, Orkin SH. An extended transcriptional network for pluripotency of embryonic stem cells. Cell 2008; 132: 1049-1061. 
7. Fang $L$, Zhang $L$, Wei W, Jin X, Wang $P$, Tong $Y$ et al. A methylation-phosphorylation switch determines Sox2 stability and function in ESC maintenance or differentiation. Mol Cell 2014; 55: 537-551.

8. Peng J, Schwartz D, Elias JE, Thoreen CC, Cheng D, Marsischky G et al. A proteomics approach to understanding protein ubiquitination. Nat Biotechnol 2003; 21: 921-926.

9. Xu P, Peng J. Characterization of polyubiquitin chain structure by middle-down mass spectrometry. Anal Chem 2008; 80: 3438-3444.

10. Chau V, Tobias JW, Bachmair A, Marriott D, Ecker DJ, Gonda DK et al. A multiubiquitin chain is confined to specific lysine in a targeted short-lived protein. Science 1989; 243 : 1576-1583.

11. Pickart CM, Fushman D. Polyubiquitin chains: polymeric protein signals. Curr Opin Chem Biol 2004; 8: 610-616.

12. Thrower JS, Hoffman L, Rechsteiner M, Pickart CM. Recognition of the polyubiquitin proteolytic signal. EMBO J 2000; 19: 94-102.

13. Bennett EJ, Shaler TA, Woodman B, Ryu KY, Zaitseva TS, Becker CH et al. Global changes to the ubiquitin system in Huntington's disease. Nature 2007; 448: 704-708.

14. Cripps D, Thomas SN, Jeng Y, Yang F, Davies P, Yang AJ. Alzheimer disease-specific conformation of hyperphosphorylated paired helical filament-Tau is polyubiquitinated through Lys-48, Lys-11, and Lys-6 ubiquitin conjugation. J Biol Chem 2006; 281: 10825-10838.

15. Dammer EB, Na CH, Xu P, Seyfried NT, Duong DM, Cheng D et al. Polyubiquitin linkage profiles in three models of proteolytic stress suggest the etiology of Alzheimer disease. J Biol Chem 2011; 286: 10457-10465.

16. Puram SV, Bonni A. Novel functions for the anaphase-promoting complex in neurobiology Semin Cell Dev Biol 2011; 22: 586-594.

17. Avilion AA, Nicolis SK, Pevny LH, Perez L, Vivian N, Lovell-Badge R. Multipotent cell lineages in early mouse development depend on SOX2 function. Genes Dev 2003; 17: 126-140.

18. Ellis $\mathrm{P}$, Fagan BM, Magness ST, Hutton S, Taranova O, Hayashi S et al. SOX2, a persistent marker for multipotential neural stem cells derived from embryonic stem cells, the embryo or the adult. Dev Neurosci 2004; 26: 148-165.

19. Suh $\mathrm{H}$, Consiglio A, Ray J, Sawai T, D'Amour KA, Gage FH. In vivo fate analysis reveals the multipotent and self-renewal capacities of Sox $2+$ neural stem cells in the adult hippocampus. Cell Stem Cell 2007; 1: 515-528.

20. Garnett MJ, Mansfeld J, Godwin C, Matsusaka T, Wu J, Russell P et al. UBE2S elongates ubiquitin chains on APC/C substrates to promote mitotic exit. Nat Cell Biol 2009; 11 1363-1369.

21. Wu T, Merbl Y, Huo Y, Gallop JL, Tzur A, Kirschner MW. UBE2S drives elongation of K11. linked ubiquitin chains by the anaphase-promoting complex. Proc Natl Acad Sci USA 2010; 107: $1355-1360$

22. Meyer HJ, Rape M. Enhanced protein degradation by branched ubiquitin chains. Cell 2014; 157: $910-921$.

23. Peters JM. The anaphase promoting complex/cyclosome: a machine designed to destroy. Nat Rev Mol Cell Biol 2006; 7: 644-656.

24. Williamson A, Wickliffe KE, Mellone BG, Song L, Karpen GH, Rape M. Identification of a physiological E2 module for the human anaphase-promoting complex. Proc Natl Acad Sci USA 2009; 106: 18213-18218.

25. Boyer LA, Lee TI, Cole MF, Johnstone SE, Levine SS, Zucker JP et al. Core transcriptional regulatory circuitry in human embryonic stem cells. Cell 2005; 122: 947-956.

26. Thomson M, Liu SJ, Zou LN, Smith Z, Meissner A, Ramanathan S. Pluripotency factors in embryonic stem cells regulate differentiation into germ layers. Cell 2011; 145: 875-889.

27. Daniels DL, Weis WI. Beta-catenin directly displaces Groucho/TLE repressors from Tcf/Lef in Wnt-mediated transcription activation. Nat Struct Mol Biol 2005; 12: 364-371.

28. Martello G, Sugimoto T, Diamanti E, Joshi A, Hannah R, Ohtsuka S et al. Esrrb is a pivotal target of the Gsk3/Tcf3 axis regulating embryonic stem cell self-renewal. Cell Stem Cell 2012; 11: 491-504.

29. Sierra J, Yoshida T, Joazeiro CA, Jones KA. The APC tumor suppressor counteracts betacatenin activation and H3K4 methylation at Wnt target genes. Genes Dev 2006; 20: 586-600.

30. Ye X, Wu F, Wu C, Wang P, Jung K, Gopal K et al. Beta-catenin, a Sox2 binding partner, regulates the DNA binding and transcriptional activity of Sox2 in breast cancer cells. Cell Signal 2014; 26: 492-501.

31. Festuccia N, Osorno R, Halbritter F, Karwacki-Neisius V, Navarro P, Colby D et al. Esrrb is a direct Nanog target gene that can substitute for Nanog function in pluripotent cells. Cell Stem Cell 2012; 11: 477-490.

32. Mitsui K, Tokuzawa Y, Itoh H, Segawa K, Murakami M, Takahashi K et al. The homeoprotein Nanog is required for maintenance of pluripotency in mouse epiblast and ES cells. Cell 2003; 113: $631-642$.

33. Tremblay GB, Kunath T, Bergeron D, Lapointe L, Champigny C, Bader JA et al. Diethylstilbestrol regulates trophoblast stem cell differentiation as a ligand of orphan nuclear receptor ERR beta. Genes Dev 2001; 15: 833-838.
34. Buganim Y, Faddah DA, Cheng AW, Itskovich E, Markoulaki S, Ganz K et al. Single-cell expression analyses during cellular reprogramming reveal an early stochastic and a late hierarchic phase. Cell 2012; 150: 1209-1222.

35. Buganim Y, Markoulaki S, van Wietmarschen N, Hoke H, Wu T, Ganz K et al. The developmental potential of iPSCs is greatly influenced by reprogramming factor selection. Cell Stem Cell 2014; 15: 295-309.

36. Papp B, Plath K. Pluripotency re-centered around Esrrb. EMBO J 2012; 31: 4255-4257.

37. Takahashi K, Yamanaka S. Induction of pluripotent stem cells from mouse embryonic and adult fibroblast cultures by defined factors. Cell 2006; 126: 663-676.

38. Cavallaro M, Mariani J, Lancini C, Latorre E, Caccia R, Gullo F et al. Impaired generation of mature neurons by neural stem cells from hypomorphic Sox2 mutants. Development 2008; 135: 541-557.

39. Cimadamore F, Fishwick K, Giusto E, Gnedeva K, Cattarossi G, Miller A et al. Human ESCderived neural crest model reveals a key role for SOX2 in sensory neurogenesis. Cell Stem Cell 2011; 8: 538-551.

40. Fauquier T, Rizzoti K, Dattani M, Lovell-Badge R, Robinson IC. SOX2-expressing progenitor cells generate all of the major cell types in the adult mouse pituitary gland. Proc Natl Acad Sci USA 2008; 105: 2907-2912.

41. Taranova OV, Magness ST, Fagan BM, Wu Y, Surzenko N, Hutton SR et al. SOX2 is a dosedependent regulator of retinal neural progenitor competence. Genes Dev 2006; 20: $1187-1202$.

42. Dailey L, Basilico C. Coevolution of HMG domains and homeodomains and the generation of transcriptional regulation by Sox/POU complexes. J Cell Physiol 2001; 186: 315-328.

43. Kamachi Y, Uchikawa M, Tanouchi A, Sekido R, Kondoh H. Pax6 and SOX2 form a co-DNAbinding partner complex that regulates initiation of lens development. Genes Dev 2001; 15 : 1272-1286.

44. Sarkar A, Hochedlinger $\mathrm{K}$. The sox family of transcription factors: versatile regulators of stem and progenitor cell fate. Cell Stem Cell 2013; 12: 15-30.

45. Wilson M, Koopman P. Matching SOX: partner proteins and co-factors of the SOX family of transcriptional regulators. Curr Opin Genet Dev 2002; 12: 441-446.

46. Lai YS, Chang CW, Pawlik KM, Zhou D, Renfrow MB, Townes TM. SRY (sex determining region Y)-box2 (Sox2)/poly ADP-ribose polymerase 1 (Parp1) complexes regulate pluripotency. Proc Natl Acad Sci USA 2012; 109: 3772-3777.

47. Adachi K, Nikaido I, Ohta H, Ohtsuka S, Ura H, Kadota M et al. Context-dependent wiring of Sox2 regulatory networks for self-renewal of embryonic and trophoblast stem cells. Mol Cell 2013; 52: 380-392.

48. Bernstein BE, Mikkelsen TS, Xie X, Kamal M, Huebert DJ, Cuff J et al. A bivalent chromatin structure marks key developmental genes in embryonic stem cells. Cell 2006; 125: 315-326.

49. Loh YH, Wu Q, Chew JL, Vega VB, Zhang W, Chen X et al. The Oct4 and Nanog transcription network regulates pluripotency in mouse embryonic stem cells. Nat Genet 2006; 38: 431-440.

50. Sussman RT, Stanek TJ, Esteso P, Gearhart JD, Knudsen KE, McMahon SB. The epigenetic modifier ubiquitin-specific protease 22 (USP22) regulates embryonic stem cell differentiation via transcriptional repression of sex-determining region Y-box 2 (SOX2). J Biol Chem 2013; 288: 24234-24246.

51. Baltus GA, Kowalski MP, Zhai H, Tutter AV, Quinn D, Wall D et al. Acetylation of sox2 induces its nuclear export in embryonic stem cells. Stem Cells 2009; 27: 2175-2184.

52. Jeong CH, Cho YY, Kim MO, Kim SH, Cho EJ, Lee SY et al. Phosphorylation of Sox2 cooperates in reprogramming to pluripotent stem cells. Stem Cells 2010; 28: 2141-2150.

53. Lefebvre V, Dumitriu B, Penzo-Mendez A, Han Y, Pallavi B. Control of cell fate and differentiation by Sry-related high-mobility-group box (Sox) transcription factors. Int $J$ Biochem Cell Biol 2007; 39: 2195-2214.

54. Brown NG, Watson ER, Weissmann F, Jarvis MA, VanderLinden R, Grace CR et al. Mechanism of polyubiquitination by human anaphase-promoting complex: RING repurposing for ubiquitin chain assembly. Mol Cell 2014; 56: 246-260.

55. Kelly A, Wickliffe KE, Song L, Fedrigo I, Rape M. Ubiquitin chain elongation requires E3dependent tracking of the emerging conjugate. Mol Cell 2014; 56: 232-245.

56. Liao B, Jin Y. Wwp2 mediates Oct4 ubiquitination and its own auto-ubiquitination in a dosage-dependent manner. Cell Res 2010; 20: 332-344.

57. Buckley SM, Aranda-Orgilles B, Strikoudis A, Apostolou E, Loizou E, Moran-Crusio K et al. Regulation of pluripotency and cellular reprogramming by the ubiquitin-proteasome system. Cell Stem Cell 2012; 11: 783-798.

58. Gregory MA, Qi Y, Hann SR. Phosphorylation by glycogen synthase kinase-3 controls c-myc proteolysis and subnuclear localization. J Biol Chem 2003; 278: 51606-51612.

59. Reynolds A, Leake D, Boese Q, Scaringe S, Marshall WS, Khvorova A. Rational siRNA design for RNA interference. Nat Biotechnol 2004; 22: 326-330.

60. Ui-Tei K, Naito Y, Takahashi F, Haraguchi T, Ohki-Hamazaki H, Juni A et al. Guidelines for the selection of highly effective siRNA sequences for mammalian and chick RNA interference. Nucleic Acids Res 2004; 32: 936-948. 